\title{
Electronic commerce
}

\section{The technological transformation of business}

\author{
by Deborah Lynn Harrington
}

$\mathrm{T}$ he exponential growth of Internet popularity and the evolution of technological capabilities have forever transformed the way business is being conducted. This transformation, the use of Internet technology to market and deliver a company's product and services over the Web, is known as electronic commerce. With only a computer, browser, and Internet connection, millions of worldwide consumers can go shopping at any time and any place to purchase such things as cars, airline tickets, flowers, prescriptions, books, and investment stocks.

The success of electronic commerce, or e-commerce, is evidenced by the value of online transactions ranging in the billions of dollars per year. Businesses, both big and small, are racing to put up virtual storefronts to take advantage of the many opportunities that exist when conducting business over the Internet.

Sales are strengthened as the Web opens new markets and offers companies the opportunity to become truly global in reach. Customer relations improve as the company provides more information and communication with customers through their Web presence and offer more one-on-one marketing for specific needs.

One of the best ways to learn about electronic commerce is to experience it in action on the Internet, where it all takes place in the virtual malls and from individual com- pany virtual storefronts. A few interesting sites to get started with include: Yahoo! Shopping (http://shopping.yahoo.com/); iCat Mall (http://mall.icat.com/mall/); iMall (http:// www.imall.com); and Amazon Books (http:// www.amazon.com).

Electronic commerce is only in its infancy, and the opportunities for both business and consumer are limitless. Taking advantage of opportunities requires both a knowledge of the many facets of electronic commerce and an understanding of how to successfully merge business and technology to bring it all together. The Internet provides a wealth of information resources covering every aspect of electronic commerce from tutorials to advanced technologies.

The information resources suggested here are the author's favorites and provide a general introduction to the many areas of e-commerce in the following categories: getting started, academic research centers, discussion lists and news groups, government and industry organizations, news, statistics and trends, and technology.

\section{Getting started}

- allECommerce. allECommerce, created by V-Networks Inc., is a comprehensive Web site that provides links to e-commerce news and other resources for an overview of the many facets of electronic commerce. Access: http://www.allec.com/.

\section{About the author}

Deborah Lynn Harrington is a business reference librarian at West Campus Library, Texas A\&M University, College Station, email: dharrington@tamuedu 


\section{allECommerce allEc.com}

\section{Interiet-Based ECommerce News, Resources and Business Strategy}

- E-Commerce Research Room. "The Internet's largest and most comprehensive ecommerce resource and portal site," it provides numerous links to articles and resources for specific issues in e-commerce. Also see the link to the Web Marketing Info Center (http://www.wilsonweb.com/marketing/) for additional information. Access: http:// www webcommercetoday.com/research/.

- ecProfessional. Globeset, an electronic transaction software consulting firm, created this educational site especially for professionals involved in the business of electronic commerce. Access: http://www.globeset. $\mathrm{com} /$ Commerce/.

- eMarketer. A one-stop resource created by eMarketer, providing information and resources on how to build, promote, and maintain a successful Web site. Links include news, statistics, top ten listing of the best e-commerce sites, a tutorial, a list of Web resources, an eforum, and statistical reports. Access: http:// www.emarketer.com/.

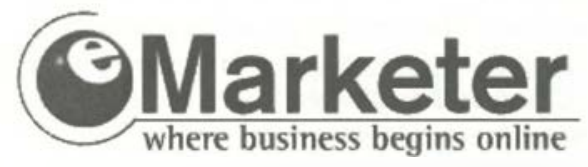

- Internet Advertising Resource Guide. Hairong Li, a professor of advertising at Michigan State University, created this comprehensive site that provides information for Internet advertising. Category links include: introduction, planning, development, management, research, and teaching. Access. http:// www.admedia.org/.

- Webmonkey: e-business collection. Wired Digital, the company that created the HotBot search engine (http://www.hotbot. com) and produces Wired magazine, has designed the Webmonkey collections to introduce and provide resources for specific Internet technologies. The e-business collection is an introductory guide to e-commerce. Useful links for newbies include an e-commerce tutorial, a guide to creating a Web site for a small business, a guide for conducting your own market research on the Web, and other infor- mation links, which are arranged into categories. Access: http://www.hotwired.com/ webmonkey/e-business/.

\section{Academic research centers}

- Center for Research in Electronic Commerce (University of Texas, Austin). This leading research center is focused on supporting research and education in the areas of electronic commerce and digital products. Links on the site provide access to electronic commerce Web sites, working papers and articles, publications, and news. Access: http://cism.bus.utexas.edu/

- Project 2000 (Owen Graduate School of Management, Vanderbilt University). This project, created by Donna Hoffman and Tom Novak, was one of the first academic research projects organized "to study the marketing implications of commercializing the World Wide Web." This site includes a complete detailed list of all Project 2000 working papers and a directory of useful resource links for marketing and electronic commerce. $A C$ cess: http://ecommerce.vanderbilt.edu/.

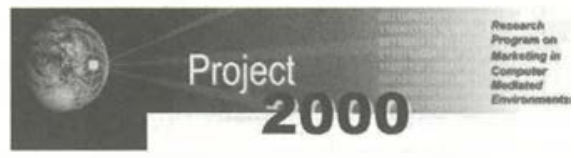

\section{Discussion lists and news groups}

- E-Marketing Digest. An educational forum created by Webber's Communication for the discussion of online marketing issues. Subscribers may opt for either a live chat ver-

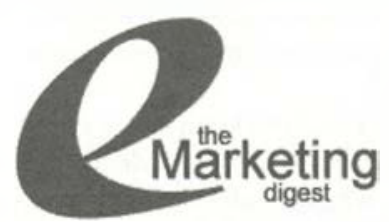
sion or a moderated digest version that provides news, information, tips, source awareness, and a reader's discussion area. Access: http://www.webbers.com/emark/.

- I-Advertising (The Internet Advertising Discussion List). This is a moderated forum for the discussion of the commercial 


\section{ه}

uses of advertising in promoting a business on the Internet. Access: http://www. internetadvertising. org/.

\section{- I-Sales (Internet}

Sales). John Audette, president of Multimedia Marketing Group, moderates this discussion list that provides a forum for the discussion of online sales issues. Access: http://www.mmgco.com/isales/.

\section{(2)}

\section{Internet-Sales}

- LearningFOUNT. A discussion community, created as an idea incubator, that provides a forum to discuss, network, and brainstorm electronic commerce issues. Access: http://www.learningfountain.com/ mailist.htm.

- Markethink (All Marketing Discussion List). Moderated virtual discussion group, covering both Internet and traditional marketing, whose focus is learning, networking, succeeding, and community. Access: http://www.markethink.com/digest.

\section{Newsgroups}

- alt.ecommerce

- alt.internet.commerce

- alt.www.marketing

\section{Government and industry organizations}

- CommerceNet. This leading industry consortium focuses on emerging global and industry-wide issues and technologies that promote the growth and success of e-commerce. CommerceNet provides links to news, a conference listing, e-commerce resources, a research center that provides demographic data and reports, and a forum for initiating global partnerships. Access. http:// www.commercenet.com/.

- Computer Security Resource Clearinghouse (National Institute of Standards and Technology). This Web site was created to provide systems personnel with computer security information resources to bet- ter protect their data and systems. Links are provided to computer security resources including NIST research topics, a list of conferences, organizations, United States policies and documents, publications, and training resources. Access: http://csrc.nist.gov/.

- Electronic Commerce Resource Center (ECRC). This educational site was created to assist industrial enterprises, which supply goods and services to the Department of Defense and other federal organizations, to adopt e-commerce. A link to "Regional ECRC Contacts" is available on the main page. Each regional ECRC maintains a Web site of outreach, education, and training materials. Access: http://www.ecrc.ctc. $\mathrm{com} /$.

- Federal Electronic Commerce Program Office. This educational site was created for governmental agencies providing awareness of the best ideas and resources in e-commerce. Includes links to EC topics arranged

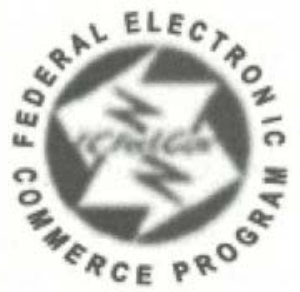
into several categories and federal EC Web sites. Access: http:// ec.fed.gov/.

- Manufacturing Information Resource Locator. This site was created to support and educate staff working in centers sponsored by the Manufacturing Extension Partnership (MEP) of the National Institute of Standards and Technology. Provides an FAQ section, a glossary, Web resources by industry sector, and several tutorials including a primer, implementation guide, and guide to managing change. Access: http://www. nemonline.org $/ \mathrm{mirl} / \mathrm{ec} /$.

- United States Government Electronic Commerce Policy. This is the official government site for electronic commerce policy, which provides links to official press releases, U.S. government documents and reports, and selected e-commerce Internet resources for government, international, and e-commerce. Access: http://www.doc.gov/ ecommerce/.

- w3C World wide Web Consortium. W3C is an international industry consortium dedicated to developing common Web protocols. This site provides a wealth of tech- 
nology related links. Access: http://www. w3.org

\section{News}

- e-business (ZDNet). An e-journal that provides e-commerce headlines as well as links to tech resources, reviews, downloads, and more. Access. http://www.zdnet.com/enterprise/e-business/.

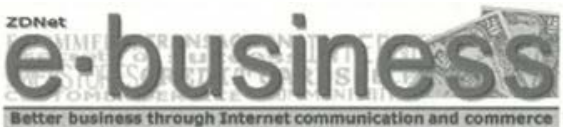

- e-commerce news (internet.com

Corp.). News site providing the latest e-commerce news headlines. Links are also provided to other news sections including: InternetNews Front Page, Business News, Intranet News, ISP News, Product News, and Web Developer News, among others. Also see the internet.com main page (http://www. internet.com/) for a more comprehensive resource listing. Access: http://www. internetnews.com/ec-news/.

- E-Commerce Times. Designed and produced by Wide Cast Media for the Triad Group, LLC, this site is "For industry insiders covering all the latest news and analysis." It provides links to sections covering news, special reports, products and services, a small business advisor, e-commerce jobs, a message board, and event calendar. Access: http:// www.ecommercetimes.com/.

- The Industry Standard (The Newsmagazine of the Internet Economy). This e-journal covers "the people, the companies, and the business models shaping the Internet Economy," It includes sections that provide news, business model reviews, personality profiles, industry metrics, and executive job recruiting. Access: http:// www.thestandard.com/.

- Yahoo! Electronic Commerce News. Latest electronic news headlines are compiled here from a number of sources. Links to consumer- and business-related Web sites are also provided. Access: http://headlines yahoo. $\mathrm{com} /$ Full_Coverage/Tech/Electronic_ Commerce/.

\section{Statistics/trends}

- Cyber Atlas (internet.com Corp). Provides statistics and Web marketing informa- tion gathered from key data sources to enable marketers to make decisions based on the latest online facts. Access: http:// cyberatlas.internet.com.

\section{EyberAtlas}

- GVU's Www User Surveys. Provides links to comprehensive surveys that have been periodically produced by Georgia Tech's College of Computing. Survey results provide comprehensive data, graphs, and charts and are arranged into detailed categories including demographics, technology, and Internet shopping. Access: http://www.gvu.gatech. edu/user_surveys/.

- Headcount.com (International Communications, Inc.). International Marketing, Inc., an Internet consulting firm specializing in localization and translation services, created this site to provide statistics on the size of specific Internet populations to assist businesses in globalization efforts. Data is gathered from various market research firms and is rated and summarized for international marketers. Counts are provided by country, language, and region and comparison reports are available. Access. http:/ /www.headcount.com/.

- Internet Economy Indicators (University of Texas). The Internet Economy Indicators tracks the growth of the Internet economy by measuring the sales volume and employment in various groups of Internetrelated products and services. This site provides links to facts and figures covering the U.S. and global Internet economy as well as resource links to financial markets, media, government, and Internet organizations. $A C$ cess: hitp://www.internetindicators.com/ index.html.

- NUA Internet Surveys. NUA, an Internet publishing consulting firm, provides information on Internet demographics and trends. Information is organized into several categories including: sectors (inclustry information), social, technical, demographics, and area (regional areas). Access: http:// www.nua.ie/surveys/about/index.html.

- StatMarket. Created by Web Side Story, this Web site provides raw and real-time data on Internet usage computed from monitoring 
millions of daily Internet visitors to Web sites using HitBOX Technology. Data categories include Web browsers, systems, globalization, traffic, major players, rush hour, and repeat visitors. Access: http://www.statmarket.com/.

\section{Technology}

- EBoz! Your Guide To Creating Successful Websites. Created by Michael Wong, this comprehensive site was created to provide the resources and tools necessary for creating successful electronic commerce Web sites. Links are provided to directories, articles, advice, tools, and shopping. Access: http://www.eboz.com/.

\section{eBoz!}

Your Guide To Lreating Suacessful websites

- EC/EDI And EC/CALS Information

Center. Integrated Technologies designed this Center for EC practitioners and researchers and provides a directory to over 2,100 Web sites covering EDI, XML, Y2K, CALS, and EC. Access: http://edi-info-center.com/.
- The eCommerce Guidebook. This educational site, created by Net Nation Communications, Ltd., provides a step-by-step guide to the process of becoming e-commerce enabled, a clirectory of all online transaction providers and a condensed summary of the prices and services they offer, and a compilation of Web resources for constructing a Web presence. Access: http://www.onlinecommerce.com/.

- Electronic Commerce Knowledge Center (ECKC). This "Comprehensive online sourcebook and information center for electronic commerce technologies" was created by the Foundation for Strategic Enterprise Knowledge Center as an unbiased information resource for learning about technologies. After a free registration process, access is provided to four centers which include: Data Warehousing, Electronic Commerce, Small Office Home Office, and Telecommuting. Each center provides links to a tutorial, Web resources by category, vendors, products, services, associations, events, and local media. Access: http://www.commerce.org/default. asp.

\section{ATLA}

American Theological Library Association

\section{Serials on Microfilm}

During the past 20 years, ATLA has affirmed its mission to preserve the scholarly literature of religion for future researchers. The ATLA microfilm collection of serial titles now includes nearly 2000 fully cataloged entries. A complete list of serial titles is available on the internet at:

\section{http://www.atla.com/products/preservation/serials.html}

Price for ATLA Institutional members: $\$ 60 \sim$ Price for others: $\$ 115$

Price for non-members is determined by Scholarly Resources and is subject to change.

Please direct your inquiries and orders to:

Scholarly Resources, Inc.,

104 Greenhill Avenue, Wilmington, DE 19805-1897 USA

Toll-free telephone (US): (800) 772-8937; Outside US: (302) $654-7713$

Fax: (302) 654-3871; E-mail: sales@scholarly.com

For information on other ATLA preservation products, contact Rick Adamek at radamek@atla.com or (888) 665.ATLA 


\section{Tables of Contents}

Would you like to increase circulation by $45 \%$ ?

Would you like to increase access up to $600 \%$ without adding one more book to your collection?

Then Blackwell's Tables of Contents service is for you! Studies have shown that adding tables of contents to your catalog records can achieve these remarkable results.

Dust jacket summaries and author affiliations can be added to your MaRC record along with content notes - all for the same price and for less than you could key them.

If you would like to know more about Blackwell's Tables of Contents service, contact Marylou Colver:

\section{BLACKWEE'S}

BOOKSERVICES

Lake Oswego - Blackwood · Oxiord Sydney

For more information contact: 6024 SW Jean Road, Building G

Lake Oswego, Oregon 97035

Telephone: 1-800-547-6426

E-mail: toc@blackwell.com Internet: http://www.blackwell.com 